\title{
Up-regulation of Cytoplasmic CD24 Expression Is Associated with Malignant Transformation but Favorable Prognosis of Colorectal Adenocarcinoma
}

\author{
MIN-KYUNG YEO, YONG-MOON LEE, IN-OCK SEONG, SONG-YI CHOI, KWANG-SUN SUH, \\ KYU SANG SONG, CHOONG-SIK LEE, JIN MAN KIM and KYUNG-HEE KIM
}

Department of Pathology, Chungnam National University School of Medicine, Daejeon, Republic of Korea

\begin{abstract}
Aim: Cluster of differentiation 24 (CD24) is known to be a putative marker of stem cell and tumor metastasis. This study aimed to verify the clinicopathological value of CD24 expression in colorectal adenocarcinoma (CRAC). Materials and Methods: A total of seven wholetissue sections of malignant polyps including the sequence non-neoplastic colorectal tissue-adenoma-CRAC, 48 adenomas and 161 CRACs arranged as tissue microarray were examined by immunohistochemistry for CD24 protein expression. Association of CD24 expression with clinicopathological parameters were also studied. Results: CD24 was not detected in normal mucosal epithelia. Cytoplasmic CD24 expression was higher in CRAC than in adenoma $(p<0.001)$. In CRACs, cytoplasmic CD24 expression was inversely correlated with poor differentiation (grades 1 to 3), tumor size, and pathological TNM stage (I to III versus IV) ( $p=0.005, p=0.034$, and $p=0.006$, respectively). Statistical correlations between high CD24 expression and longer overall and disease-free survival were found ( $p=0.023$ and $p=0.033$, respectively). Conclusion: Our findings suggest that up-regulation of CD24 expression in CRAC occurs at malignant transformation but is a marker of good prognosis, being down-regulated in pathological TNM stage IV. CD24 expression may be a challenging diagnostic marker in differentiating early invasive CRAC from adenoma and may serve as a prognostic marker in patients with CRAC.
\end{abstract}

This article is freely accessible online.

Correspondence to: Kyung-Hee Kim, Department of Pathology, Cancer Research Institute, Chungnam National University, School of Medicine, 266 Munhwa Street, Jung-gu, Daejeon 35015, Republic of Korea. Tel: +82 425808238, Fax: +82 422807189, email: phone330@cnu.ac.kr and Jin Man Kim, Tel: +82 425808237, Fax: +82 422807189, e-mail: jinmank@cnu.ac.kr

Key Words: CD24, colorectal adenocarcinoma, adenoma.
Cluster of differentiation 24 (CD24), a small glycosylated cell surface protein, was first reported as a glycosylphosphatidylinositol (GPI)-linked B-cell-related antigen in humans (1). CD24 is physiologically expressed in various developing cells, not just in pre-B-cells but also in keratinocytes, renal tubules, developing epithelial cells, and regenerating muscles (2-5). CD24 has raised considerable interest in tumor biology, with functions in regulation of cell-to-cell interaction, cell growth, cell motility and invasion $(6,7)$. CD24 overexpression has been identified in many cancer types, including hematological, breast, lung, prostate, and gastrointestinal cancer (8-14). CD24 has also gained attention as a potential marker for tumor stem cells with other molecules such as CD44 and CD133 by demonstrating tumorigenenic ability (15-17).

Colorectal adenocarcinoma (CRAC), which is one of the most common types of cancer in humans, is a leading cause of mortality. CRAC is curative at an early stage but prognosis is poor if it metastasizes (18). Prognostic factors, such as tumor stage, histological type, tumor grade, and surgical margins, are well known for CRAC (19). In addition to these conventional factors, molecular markers are being researched to find diagnostic, prognostic, and therapeutic implications for CRAC. CD24 protein overexpression has been shown to be significant in gastrointestinal tract cancer, including CRAC (6).

CD24 expression has been reported to be commonly upregulated in CRAC and benign adenoma $(20,21)$ and has been shown to be a marker of poor prognosis (22). CRAC typically develops in a multistep process to malignancy, through various genetic alterations (20). We aimed to verify CD24 protein expression patterns by immunohistochemical staining in non-neoplastic epithelia, adenoma and CRAC, and to determine the correlation between CD24 expression and clinicopathological parameters, including patient survival.

\section{Materials and Methods}

Patients and specimens. We obtained 216 paraffin-embedded colorectal samples collected from 216 patients who underwent curative resection at the Chungnam National University Hospital, Daejeon, South Korea, between 2002 and 2015. The tissues 
consisted of seven whole-tissue samples of malignant polyps including the sequence non-neoplastic colorectal tissue-adenomaCRAC, 48 tissue microarray samples of adenoma with low-grade dysplasia, and 161 tissue microarray samples of CRAC. None of the patients had received preoperative chemotherapy or radiotherapy. These specimens were provided by the National Biobank of Korea, Chungnam National University Hospital, Daejeon, South Korea. This study was approved by the Institutional Review Board of the Chungnam National University Hospital (CNUH 2016-04-038).

All cases were clinicopathologically reviewed by two pathologists (KHK and MKY), and the two most representative areas of viable tissue were selected and marked on the hematoxylin and eosin-stained slides. Tissue microarray was created by punching tissue columns ( 2.0 or $3.0 \mathrm{~mm}$ in diameter) from the original paraffin blocks and inserting them into new recipient paraffin blocks (each containing 30 holes for tissue columns). The CRAC stages were determined according to the Seventh Edition of the American Joint Committee on Cancer Staging System (23).

Immunohistochemical analysis. The embedded tissue sections on the microslides were deparaffinized with xylene and hydrated in a graded alcoholic series. The sections were heated in a pressure cooker containing $10 \mathrm{mmol} / 1$ sodium citrate $(\mathrm{pH} 6.0)$ for $3 \mathrm{~min}$ at full power for antigen retrieval. Endogenous peroxidase activity blocking was performed using $0.03 \%$ hydrogen peroxide containing sodium azide for $5 \mathrm{~min}$. The sections were incubated at room temperature for $1 \mathrm{~h}$ with primary monoclonal mouse antibody to CD24 (diluted 1:100; Abcam, Cambridge, UK). The samples were washed and then incubated in labeled polymerHRP anti-mouse immunoglobulins [Dako EnVision+system-HRP (DAB), Dako, Carpinteria, CA] for an additional $20 \mathrm{~min}$ at room temperature followed by additional washing. After rinsing, the chromogen was developed for $2 \mathrm{~min}$. The slides were then counterstained with Mayer's hematoxylin, dehydrated, and coverslipped. The primary antibody was omitted in the negative controls.

All immunostained slides were digitally scanned using a scanscope (Aperio ScanScope CS System, Vista, CA, USA). Immunohistochemical staining was scored using digitally scanned files and a light microscope. We used the Allred scoring system for evaluating both the intensity of the immunohistochemical staining and the proportion of stained epithelial cells (24). The intensity score (range: 0 to 3 ) and the proportion score (range: 0 to 5 ) were added to obtain the total score (range: 0 to 8 ). For categorical survival analyses, expression at the median value or more was regarded as high CD24 expression. Each sample was examined separately and scored by two pathologists (KHK and MKY). Discrepancies in scores were discussed in order to obtain a consensus.

Statistical analysis. The associations of CD24 immunohistochemical expression and clinicopathological variables for the colorectal neoplastic lesions were examined with Spearman's rank correlation coefficient, Mann-Whitney $U$-test, and Kruskal-Wallis test. Postoperative overall and disease-free survival curves were determined using the Kaplan-Meier method. Univariate and multivariate survival analyses were assessed using log-rank test and Cox's proportional hazard regression model, respectively. Statistical significance was set at $p<0.05$ (SPSS 21; IBM Corp., Armonk, NY, USA).

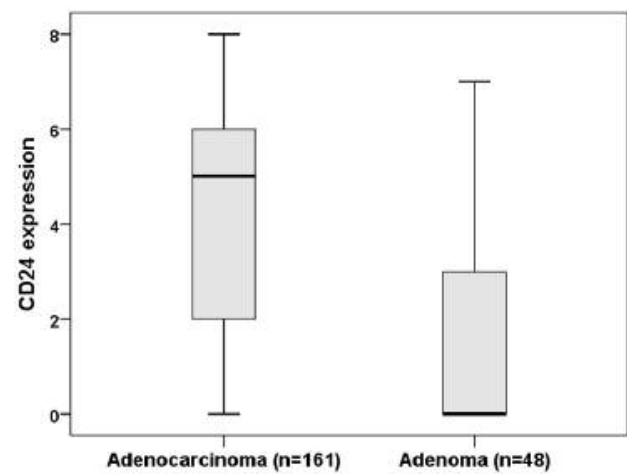

Figure 1. Comparison between the colorectal adenocarcinoma and adenoma groups of the CD24 expression (Mann-Whitney U-test: $p<0.001)$. The line in the middle of the boxes is the median. The box length indicates the interquartile range. The ends of the whiskers represent maximum and minimum values.

Table I. Correlation between CD24 expression and clinicopathological factors in 161 patients with colorectal adenocarcinoma.

\begin{tabular}{lrcc}
\hline Variable & No. & CD24 expression & $p$-Value \\
\hline Gender & & & $0.949^{\mathrm{a}}$ \\
$\quad$ Male & 99 & 5 (Median) & \\
Female & 62 & 5 (Median) & $0.005^{\mathrm{b}}$ \\
Differentiation & & & \\
$\quad$ Grade 1 & 2 & 6.5 (Median) & \\
$\quad$ Grade 2 & 142 & 5 (Median) & \\
$\quad$ Grade 3 & 17 & 0 (Median) & $0.478^{\mathrm{a}}$ \\
Nodal metastasis & & & \\
$\quad$ Absent & 81 & 5 (Median) & \\
$\quad$ Present & 80 & 5 (Median) & $0.083^{\mathrm{a}}$ \\
Pathologic stage & & & \\
I-II & 71 & 6 (Median) & \\
III-IV & 90 & 5 (Median) & $0.006^{\mathrm{a}}$ \\
Pathologic stage & & 6 (Median) & \\
I-III & 125 & 3 (Median) & \\
IV & 36 & & \\
\hline
\end{tabular}

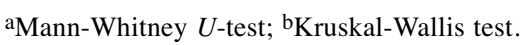

\section{Results}

Differential expression of CD24 in adenoma and CRAC. The cytoplasmic CD24 expression was evaluated in the seven whole-tissue sections of malignant polyps containing both non-neoplastic and neoplastic mucosa, a tissue microarray containing 48 adenomas with low-grade dysplasia, and six tissue microarray paraffin blocks containing $161 \mathrm{CRAC}$. The adenomas expressed significantly lower CD24 levels than did the CRACs $(p<0.001)$ (Figure 1). All non-neoplastic epithelia were negative for CD24 expression (Figure 2). 


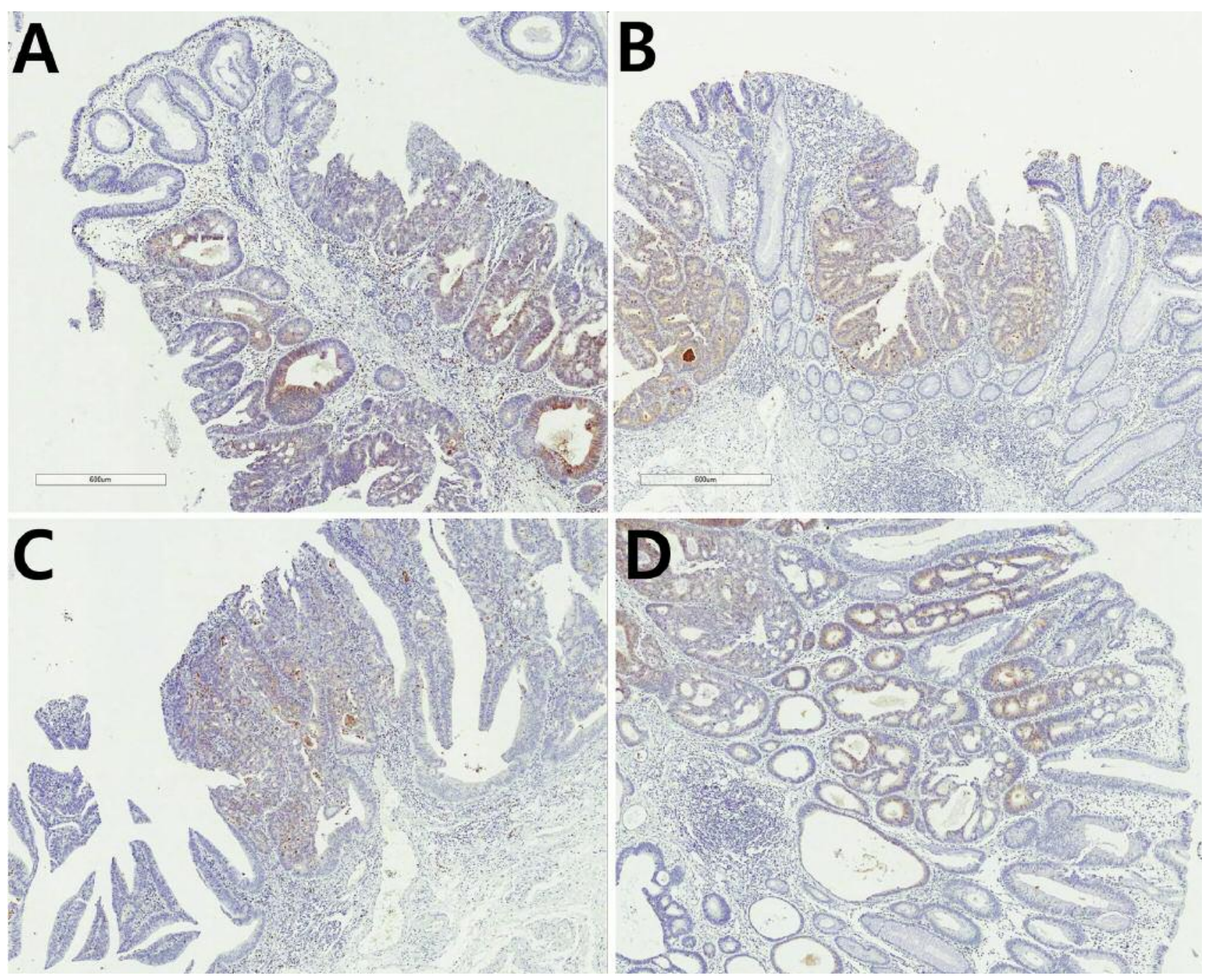

Figure 2. Representative photographs of CD24 immunostaining in four colonic malignant polyps A-D: Both normal and adenoma showed negative staining in contrast to up-regulation of cytoplasmic CD24 expression detection in micro-invasive adenocarcinomas. Scale bar: $600 \mu$ m.

Clinicopathological features and the CD24 expression pattern in CRAC. We investigated 161 tissue microarray CRAC samples with clinicopathological analysis. The 161 tissue microarray samples were of CRAC located in the ascending colon $(n=34)$, transverse colon $(n=9)$, descending colon $(n=8)$, sigmoid colon $(n=49)$, and rectum $(n=61)$. The patients ranged in age from 26 to 89 years, with a mean of 64.83 years. The 161 tumors ranged in the largest diameter from $1.0 \mathrm{~cm}$ to 12.0 $\mathrm{cm}$ with a mean of $5.13 \mathrm{~cm}$. CD24 expression negatively correlated with age, tumor size, poorly differentiated CRAC, and pathologic TNM stage (I to III versus IV) $(p=0.039$, $p=0.034, p=0.005$, and $p=0.006$, respectively) (Table I).
Both overall and disease-free survival analyses were carried out on 122 patients with CRAC among 161 tissue microarray samples from patients with CRAC. Kaplan-Meier survival curves and log-rank tests showed significant association of high CD24 expression with prolonged overall and disease-free survival ( $p=0.023$ and $p=0.033$, respectively) (Figure 3 ). Multivariate analyses using the Cox's proportional hazard regression model were performed on age, sex, and CD24 expression. The multivariate analyses showed high CD24 expression to be a prognostic factor indicative of good overall and disease-free survival ( $p=0.019$ and $p=0.045$, respectively) (Table II). 

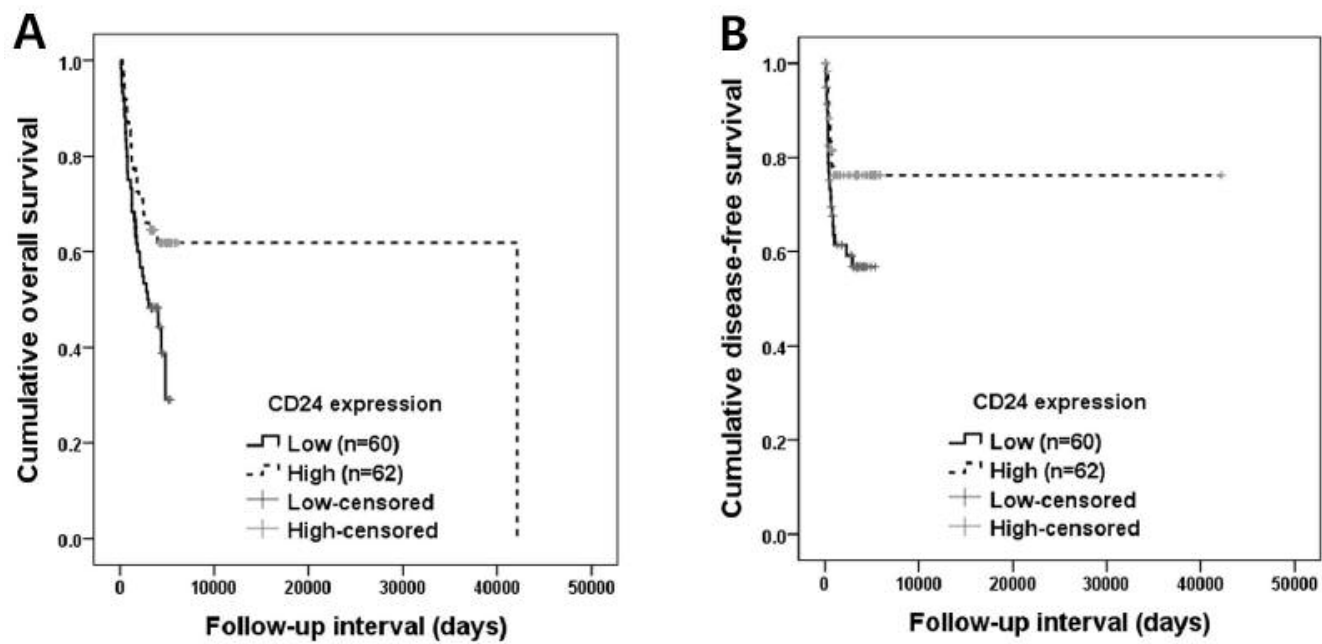

Figure 3. Kaplan-Meier survival curves according to CD24 expression in patients with colorectal adenocarcinoma $(C R A C)(n=122)$. Overall survival $(\log$-rank=5.186, $p=0.023)(A)$ and disease-free survival $(\log$-rank=4.541, $p=0.033)(B)$.

Table II. Multivariate analysis results of overall and disease-free survival in 122 patients with colorectal adenocarcinoma.

\begin{tabular}{|c|c|c|c|c|c|c|}
\hline & \multicolumn{3}{|c|}{ Overall survival } & \multicolumn{3}{|c|}{ Disease-free survival } \\
\hline & HR & $95 \% \mathrm{CI}$ & $p$-Value & HR & $95 \% \mathrm{CI}$ & $p$-Value \\
\hline CD24 (low vs. high) & 0.526 & $(0.308-0.899)$ & 0.019 & 0.506 & $(0.260-0.985)$ & 0.045 \\
\hline Sex (male $v s$. female) & 0.679 & $(0.388-1.190)$ & 0.176 & 1.487 & $(0.780-2.834)$ & 0.228 \\
\hline Age (range $=26-89$ years $)$ & 1.039 & $(1.012-1.066)$ & 0.004 & 0.980 & $(0.954-1.008)$ & 0.156 \\
\hline
\end{tabular}

HR, Hazard ratio; CI, confidence interval.

\section{Discussion}

In this study, we investigated CD24 protein expression in CRAC using immunohistochemistry. CD24 was up-regulated in human CRAC compared to non-neoplastic colonic mucosa. CD24 expression was not observed in normal epithelia, but was mildly increased in adenoma and markedly increased in CRAC. CD24 had dominant and diffuse cytoplasmic immunoreactivity. Aberrant cytoplasmic accumulation of CD24 expression could be considered a marker of early CRAC progression. Considering multivariate and univariate survival analyses, CD24 expression demonstrated a prognostic impact on CRAC. Cytoplasmic CD24 expression was inversely correlated with poor differentiation (grades 1 to 3), tumor size, and pathological TNM stage (I to III versus IV).

The significance of CD24 expression has been described for carcinogenesis and putative cancer stem cell marker characterization, but the reported results are conflicting depending on tumor cell type or localization of CD24 expression. CD24 protein overexpression was significantly associated with malignant transformation or poor survival in prostate, hepatobiliary, and gastrointestinal tract cancer (1214, 22). However, CD24 underexpression or lack of expression was also reported to have an unfavorable relationship with clinicopathological parameters in breast and ovarian cancer (25-27).

The pattern and significance of CD24 protein expression among patients with CRAC and its precursor lesion have been evaluated in CRAC. Increased CD24 expression in adenoma and carcinoma that was contrary to the low CD24 expression in normal adjacent mucosa was observed $(20,22)$. Cytoplasmic, membranous, or nuclear expression patterns of the CD24 marker were identified, even though CD24 is a membrane-bound receptor (21). Positive luminal membrane expression of CD24 by immunohistochemical staining was seen to the same extent in adenomas and all stages of CRAC, which indicates that CD24 expression is an early event in CRAC carcinogenesis (20). Cytoplasmic CD24 expression has generally been shown to correlate with higher tumor grade, higher tumor stage, and metastasis, and was a marker 
of poor prognosis in CRAC $(22,28-30)$. However, no prognostic significance or loss of CD24 expression in relation to poor outcome and unfavorable parameters in CRAC has also been reported $(21,31,32)$.

A recent study of pancreatic ductal adenocarcinomas showed that CD24 expression was exclusively up-regulated in well-differentiated tumors, whereas CD24 expression was absent in undifferentiated tumors (33). Our study supports the previous study's proposal that cytoplasmic CD24 expression inhibits tumor cell migration thus inhibiting undifferentiated features $(33,34)$.

In conclusion, our results demonstrate that up-regulation of cytoplasmic CD24 expression in CRAC occurred at malignant transformation but appears to have a favorable prognostic impact on patient survival. Although the clinical significance of CD24 is not completely understood, aberrant cytoplasmic CD24 expression may be a challenging diagnostic marker in differentiating early invasive CRAC from adenoma and serve as a potential prognostic marker in patients with CRAC.

\section{Acknowledgements}

This work was supported by a Chungnam National University research fund.

\section{References}

1 Pirruccello $\mathrm{S}$ and LeBien T: The human B cell-associated antigen CD24 is a single chain sialoglycoprotein. J Immunol 136: 3779-3784, 1986 .

2 Shirasawa T, Akashi T, Sakamoto K, Takahashi H, Maruyama N and Hirokawa K: Gene expression of $\mathrm{CD} 24$ core peptide molecule in developing brain and developing non-neural tissues. Dev Dyn 198: 1-13, 1993.

3 Figarella-Branger D, Moreau H, Pellissier J, Bianco N and Rougon G: CD24, a signal-transducing molecule expressed on human B lymphocytes, is a marker for human regenerating muscle. Acta Neuropathol 86: 275-284, 1993.

4 Redondo P, García-Foncillas J, Okroujnov I, de Felipe I and Quintanilla E: CD24 expression on human keratinocytes. Exp Dermatol 7: 175-178, 1998.

5 Droz D, Zachar D, Charbit L, Gogusev J, Chretein Y and Iris L: Expression of the human nephron differentiation molecules in renal cell carcinomas. Am J Pathol 137: 895, 1990.

6 Sagiv E and Arber N: The novel oncogene CD24 and its arising role in the carcinogenesis of the GI tract: from research to therapy. Expert Rev Gastroenterol Hepatol 2: 125-133, 2008.

7 Baumann P, Cremers N, Kroese F, Orend G, Chiquet-Ehrismann R, Uede T, Yagita H and Sleeman JP: CD24 expression causes the acquisition of multiple cellular properties associated with tumor growth and metastasis. Cancer Res 65: 10783-10793, 2005 .

8 Kristiansen G, Sammar M and Altevogt P: Tumour biological aspects of CD24, a mucin-like adhesion molecule. J Mol Histol 35: 255-262, 2004.
9 Lim SC: CD24 and human carcinoma: tumor biological aspects. Biomed Pharmacother 59(Suppl 2): S351-354, 2005.

10 Kwon MJ, Han J, Seo JH, Song K, Jeong HM, Choi J-S, Kim YJ, Lee S-H, Choi Y-L and Shin YK: CD24 Overexpression Is Associated with Poor Prognosis in Luminal A and TripleNegative Breast Cancer. PLoS One 10: e0139112, 2015.

11 Lee HJ, Choe G, Jheon S, Sung S-W, Lee C-T and Chung J-H: CD24, a novel cancer biomarker, predicting disease-free survival of non-small cell lung carcinomas: a retrospective study of prognostic factor analysis from the viewpoint of forthcoming (seventh) new TNM classification. J Thorac Oncol 5: 649-657, 2010.

12 Kristiansen G, Pilarsky C, Pervan J, Stürzebecher B, Stephan C, Jung K, Loening S, Rosenthal A and Dietel M: CD24 expression is a significant predictor of PSA relapse and poor prognosis in low grade or organ confined prostate cancer. Prostate 58: 183$192,2004$.

13 Agrawal S, Kuvshinoff BW, Khoury T, Yu J, Javle MM, LeVea C, Groth J, Coignet LJ and Gibbs JF: CD24 expression is an independent prognostic marker in cholangiocarcinoma. J Gastrointest Surg 11: 445-451, 2007.

14 Chou Y-Y, Jeng Y-M, Lee T-T, Hu F-C, Kao H-L, Lin W-C, Lai P-L, Hu R-H and Yuan R-H: Cytoplasmic CD24 expression is a novel prognostic factor in diffuse-type gastric adenocarcinoma. Ann Surg Oncol 14: 2748-2758, 2007.

15 Miki J, Furusato B, Li H, Gu Y, Takahashi H, Egawa S, Sesterhenn IA, McLeod DG, Srivastava S and Rhim JS: Identification of Putative Stem Cell Markers, CD133 and CXCR4, in hTERT-Immortalized Primary Nonmalignant and Malignant Tumor-Derived Human Prostate Epithelial Cell Lines and in Prostate Cancer Specimens. Cancer Res 67: 3153-3161, 2007.

16 Prince ME, Sivanandan R, Kaczorowski A, Wolf GT, Kaplan MJ, Dalerba P, Weissman IL, Clarke MF and Ailles LE: Identification of a subpopulation of cells with cancer stem cell properties in head and neck squamous cell carcinoma. Proc Natl Acad Sci USA 104: 973-978, 2007.

17 Li C, Heidt DG, Dalerba P, Burant CF, Zhang L, Adsay V, Wicha M, Clarke MF and Simeone DM: Identification of pancreatic cancer stem cells. Cancer Res 67: 1030-1037, 2007.

18 Siegel RL, Miller KD and Jemal A: Cancer statistics, 2015. CA Cancer J Clin 65: 5-29, 2015.

19 Compton CC, Fielding LP, Burgart LJ, Conley B, Cooper HS, Hamilton SR, Hammond MEH, Henson DE, Hutter RV and Nagle RB: Prognostic factors in colorectal cancer: College of American Pathologists consensus statement 1999. Arch Pathol Lab Med 124: 979-994, 2000.

20 Sagiv E, Memeo L, Karin A, Kazanov D, Jacob-Hirsch J, Mansukhani M, Rechavi G, Hibshoosh H and Arber N: CD24 is a new oncogene, early at the multistep process of colorectal cancer carcinogenesis. Gastroenterology 131: 630-639, 2006.

21 Ahmed M, Al-Attar A, Kim J, Watson N, Scholefield J, Durrant $\mathrm{L}$ and Ilyas M: CD24 shows early upregulation and nuclear expression but is not a prognostic marker in colorectal cancer. $\mathrm{J}$ Clin Pathol 62: 1117-1122, 2009.

22 Weichert W, Denkert C, Burkhardt M, Gansukh T, Bellach J, Altevogt P, Dietel M and Kristiansen G: Cytoplasmic CD24 expression in colorectal cancer independently correlates with shortened patient survival. Clin Cancer Res 11: 6574-6581, 2005. 
23 Edge SB BD, Compton CC, Fritz AG, Greene FL and Trotti A: AJCC Cancer Staging Manual. Seventh Edition. New York, NY, Springer, pp. 143-164, 2010.

24 Allred DC, Harvey JM, Berardo M and Clark GM: Prognostic and predictive factors in breast cancer by immunohistochemical analysis. Modern Pathol 11: 155-168, 1998.

25 Kim HJ, Kim M-J, Ahn SH, Son BH, Kim SB, Ahn JH, Noh WC and Gong G: Different prognostic significance of CD24 and CD44 expression in breast cancer according to hormone receptor status. Breast 20: 78-85, 2011.

26 Sheridan C, Kishimoto H, Fuchs RK, Mehrotra S, BhatNakshatri P, Turner CH, Goulet R Jr., Badve S and Nakshatri $\mathrm{H}$ : CD44+/CD24- breast cancer cells exhibit enhanced invasive properties: an early step necessary for metastasis. Breast Cancer Res 8: R59, 2006.

27 Surowiak P, Materna V, Kaplenko I, Spaczynski M, Dietel M, Kristiansen G, Lage $\mathrm{H}$ and Zabel M: Unfavorable prognostic value of CD24 expression in sections from primary and relapsed ovarian cancer tissue. Int J Gynecol Cancer 16: 515-521, 2006.

28 Choi Y-L, Yan HX, Lee S-J, Park SM, Kim WJ, Kim H-J and Kim S-H: Enhanced CD24 expression in colorectal cancer correlates with prognostic factors. Korean J Pathol 40: 103-111, 2006.

29 Seo KJ, Kim M and Kim J: Prognostic implications of adhesion molecule expression in colorectal cancer. Int J Clin Exp Pathol 8: 4148-4157, 2015.
30 Wang W, Wang X, Peng L, Deng Q, Liang Y, Qing H and Jiang $\mathrm{B}$ : CD24-dependent MAPK pathway activation is required for colorectal cancer cell proliferation. Cancer Sci 101: 112-119, 2010.

31 Nosrati A, Naghshvar F, Maleki I and Salehi F: Cancer stem cells CD133 and CD24 in colorectal cancers in Northern Iran. Gastroenterol Hepatol Bed Bench 9: 132-139, 2016.

32 Choi D, Lee HW, Hur KY, Kim JJ, Park G-S, Jang S-H, Song YS, Jang K-S and Paik SS: Cancer stem cell markers CD133 and CD24 correlate with invasiveness and differentiation in colorectal adenocarcinoma. World J Gastroenterol 15: 22582264, 2009.

33 Lubeseder-Martellato C, Hidalgo-Sastre A, Hartmann C, Alexandrow K, Kamyabi-Moghaddam Z, Sipos B, Wirth M, Neff F, Reichert M, Heid I, Schneider G, Braren R, Schmid RM and Siveke JT: Membranous CD24 drives the epithelial phenotype of pancreatic cancer. Oncotarget doi: 10.18632/ oncotarget.9402, 2016.

34 Taniuchi K, Nishimori I and Hollingsworth MA: Intracellular CD24 inhibits cell invasion by posttranscriptional regulation of BART through interaction with G3BP. Cancer Res 71: 895-905, 2011.

Received September 22, 2016

Revised October 4, 2016

Accepted October 7, 2016 